\title{
Characterization of the weld line zones of an inertia friction welded superalloy
}

\author{
Z.W. Huang ${ }^{1 \mathrm{a}}$, H.Y. Li ${ }^{1 \mathrm{~b}}$, G. Baxter ${ }^{2 \mathrm{c}}$, S. Bray ${ }^{2 \mathrm{~d}}$ and P. Bowen ${ }^{1 \mathrm{e}}$ \\ 1. School of Metallurgy and Materials, The University of Birmingham, Birmingham B15 2TT, \\ United Kingdom \\ 2. .Rolls-Royce plc. Derby DE24 8BJ, United Kingdom \\ a z.w.huang@bham.ac.uk, bh.y.li.1@bham.ac.uk, 'cgavin.baxter@rolls-royce.com, \\ dsimon.bray@rolls-royce.com, ${ }^{\mathrm{e} p}$.bowen@bham.ac.uk
}

Key words: Nickel based superalloys, Welding, Hardening, Electron microscopy, Microanalysis

\begin{abstract}
The Inertia Friction Welding (IFW) process is a high-temperature and high pressure process, with heavy plastic deformation, high power density, fast heating and fast cooling of the weld material. The microstructure produced in the weld line (WL) zones is therefore very different from parent material. A detailed microstructural investigation of the WL zones has been conducted using transmission electron microscopy and scanning electron microscopy. It has been shown that the morphology, energy status and microchemistry of grain boundaries in the WL zones are quite different from those in the parent material. It is also observed that, compared to a bi-modal distribution of intragranular $\gamma^{\prime}$ particles in the parent material, a unimodal distribution of very fine spherical $\gamma^{\prime}$ particles is produced in high density in the WL zones. This work provides a detailed understanding of the physical and chemical changes occurring across the weld line.
\end{abstract}

\section{Introduction}

Inertia friction welding (IFW) is an attractive solid manufacturing process for joining nickel-based superalloys. Problems related to porosity and solidification defects that can occur in fusion welds are eliminated. However, the temperature at weld interface is very high, which was measured to be close to $1300^{\circ} \mathrm{C}$ [1-2], well above the solvus of any $\gamma^{\prime}$ families. All primary, secondary and tertiary $\gamma^{\prime}$ particles near the weld interface are expected to dissolve totally [3,4]. The plasticized interface region would be fully recrystallised, within which a unimodal distribution of fine-sized $\gamma^{\prime}$ particles will be re-precipitated at a very fast cooling after IFW $[1,3,4]$. It is therefore very important to understand the microstructural changes in the WL zones both in as-welded and in post-weld heat treated conditions since these changes significantly affect the mechanical properties of the welds [57]. In this study, the WL zones formed in fine grain to fine grain RR1000 welds are examined.

\section{Experimental}

The superalloy used for inertia friction welding is a powder metallurgy based polycrystalline superalloy RR1000, which was subject to a forging process. The superalloy was given a sub$\gamma^{\prime}$ solvus solution treatment to produce fine grain (FG) microstructure. A trimodal distribution of $\gamma^{\prime}$ particles, commonly termed primary, secondary and tertiary $\gamma^{\prime}$, was produced (see Figs 1a and 1b). The nominal composition of the RR1000 is detailed in Table 1. Inertia friction welding was carried out at MTI (South Bend, IN) to produce the welds. The weld obtained were then subjected to a post weld heat treatment (PWHT), followed by cooling to room temperature

Table1. RR1000 composition in wt. \%

\begin{tabular}{ccccccccccc}
\hline $\mathbf{N i}$ & $\mathbf{C r}$ & $\mathbf{C o}$ & $\mathbf{M o}$ & $\mathbf{A l}$ & $\mathbf{T i}$ & $\mathbf{T a}$ & $\mathbf{H f}$ & $\mathbf{Z r}$ & $\mathbf{C}$ & $\mathbf{B}$ \\
\hline bal & 15.0 & 18.5 & 5.0 & 3.0 & 3.6 & 2.0 & 0.5 & 0.06 & 0.027 & 0.015 \\
\hline
\end{tabular}

Metallographic samples were ground with $\mathrm{SiC}$ papers and polished to $0.25 \mu \mathrm{m}$ finish, then etched either electronically with a $10 \%$ phosphoric acid at $2-3 \mathrm{~V}$ or using a Kalling's reagent. Scanning electron microscopy (SEM) examination was carried out on a Philips XL 30 FEG scanning electron microscope, operating at 10-15 kV. Image analysis was carried out on SEM micrographs to quantify the grain size in WL zone as well as the grain size of parent material, using a mean linear-intercept method. Transmission electron microscopy (TEM) investigations were carried out on a FEI Tecnai F20 TEM machine, operating at $200 \mathrm{kV}$. Thin foils containing WL zones were then prepared by using twin-jet electro-chemical polishing with an electrolyte of $20 \%$ perchloric acid in methanol operating at $-30^{\circ} \mathrm{C}$ and a voltage of $16 \mathrm{~V}$. Energy dispersive x-ray (EDX) microanalysis on selected microstructures was performed on the TEM which is fitted with an INCA analytical EDX system. 


\section{Results and Discussion}

Recrystallised grain structure within the WL zone. Fig la shows the grain structure of FG parent RR1000 prior to welding. The average grain size was measured to be $6.0 \pm 0.3 \mu \mathrm{m}$. The large discrete primary $\gamma^{\prime}$ particles (shown as holes by Kalling's reagent) are typically located along the $\gamma$ grain boundaries, which effectively restrict grain growth during solutioning. The parent material exhibited serrated grain boundaries. Secondary and tertiary $\gamma^{\prime}$ precipitates, which distribute intragranularly in the FG RR1000, generally remain coherent with the $\gamma$ matrix, as shown in Fig. $1 \mathrm{~b}$.

On welding, dynamic recrystallisation occurred in the fully plasticized region near the weld interface where high pressure, high energy and high temperature were applied. A fully recrystallised region was formed across the weld interface. The fully recrystallised interface region is termed "weld line (WL) zone" in this paper, Fig. 2a. The width of the WL zone equals the width of primary $\gamma^{\prime}$-free zone since only this region with sufficient dissolution of primary $\gamma^{\prime}$ (white spots in Fig. 2a) can be fully plasticized and fully recrystallised during welding. The width of the WL zone across the weld interface was measured to be $\sim 220 \mu \mathrm{m}$ for the FG-FG weld. It is noticed that neither the weld line nor mixed contact interface was observable in the WL zone. This is a characteristic feature of welding the same alloy. The WL zone may be adapted by a special PWHT afterwards.

The recrystallised grain structure inside the WL zone was observed to be very different from the grain structures of parent materials in four aspects: 1) grain size, 2) grain-boundary morphology, 3) energy status and 4) microchemistry. The differences are described below in sequence.

1) Grain size. A uniform and fine grain structure formed within the fully recrystallised WL zone for the FG-FG RR1000 welds. The average grain size after full recrystallisation was measured to be $7.1 \pm 0.3 \mu \mathrm{m}$ as shown in Figs. $2 \mathrm{~b}$. This indicates that the recrystallised grains in the WL zone were similar to the parent grains of the FG RR1000.
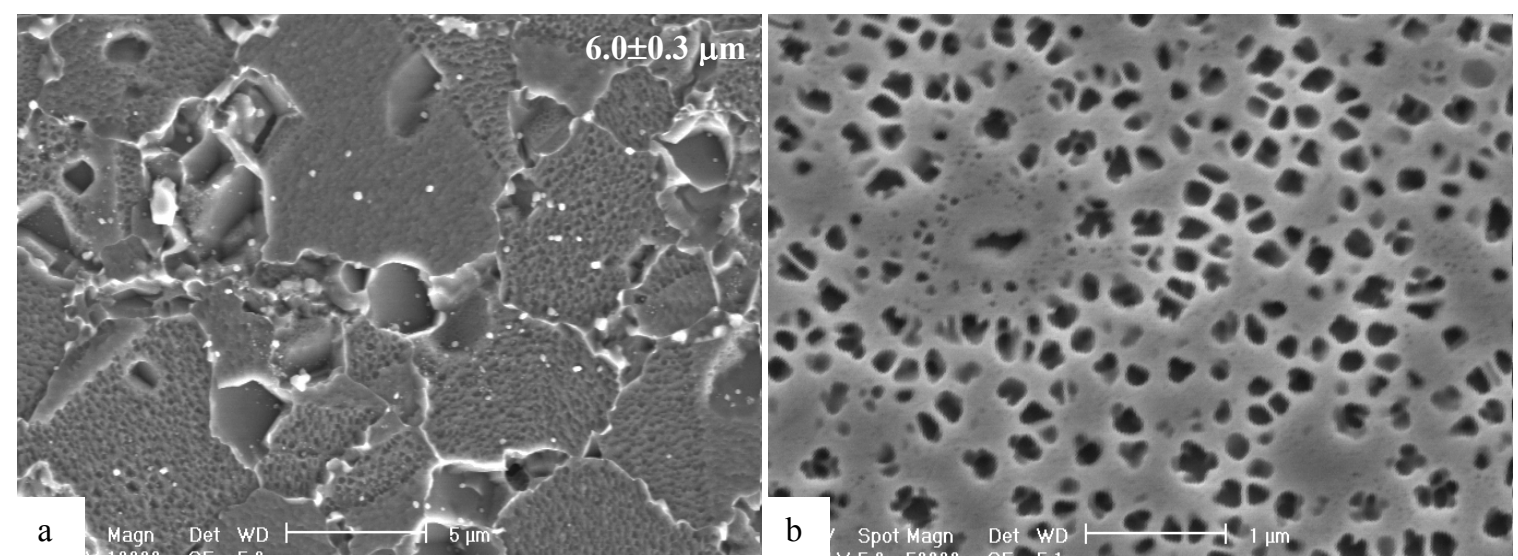

Fig.1 SEM micrographs showing the grain structure in (a) FG parent RR1000 and (b) the intragranular secondary and tertiary $\gamma^{\prime}$ particles

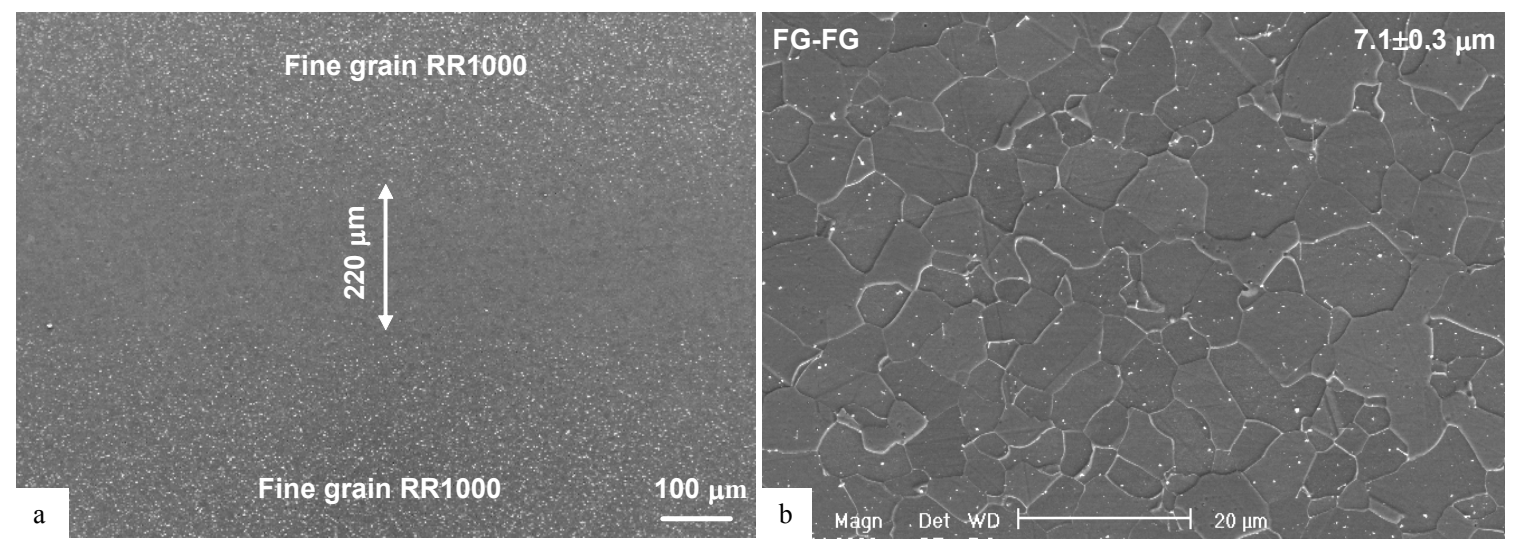

Fig. 2 SEM micrographs showing (a) the middle section of the fully recrystallised WL zone and (b) the grain structure inside the zone across the weld line for a FG-FG weld 
2) Grain boundary morphology. FG parent materials always show serrated grain boundaries (Fig. 1a) since they were produced by a relatively slow cooling $\left(1-2^{\circ} \mathrm{C} \mathrm{s}^{-1}\right)$. Unlike the parent alloys, the recrystallised grains inside the WL zone show a straight and smooth grain boundary morphology (Fig. 2b) since all these grains experienced a very fast cooling at the end of IFW operation. The significant difference in grain boundary morphology is revealed more clearly by TEM investigation. Centred dark field (CDF) image in Fig. 3a shows that the grain boundary serration in a parent RR1000 formed by slow cooling is caused by preferential growth of boundary secondary $\gamma^{\prime}$ particles towards incoherent grain boundaries (see arrows). In contrast, very fast cooling in the WL zone suppresses the effective growth of fine spherical $\gamma^{\prime}$ particles, thereby restricting the interactions of them with grain boundaries. Straight and smooth high-angle grain boundaries form as a result $[8,9]$, see Fig. $3 b$ for as-welded condition.

3) Energy status. A significant increase in stored energy in the narrow WL zone is noticed after IFW both in as-welded and in PWHT condition. The energy increase in the WL zone is typically represented by much increased dislocation density on the grain boundaries. Fig. 4a is a TEM CDF image showing a relatively clean grain boundary in a FG parent RR1000. This image was taken by using a double diffraction spot generated from the inclined grain boundary (see the insert) where the grain A and grain B were overlapped. The convoluted high angle grain boundary was illuminated, exhibiting thickness fringes with almost no dislocations on the boundary. In contrast, a high density of dislocations was observed to segregate on grain boundaries in the as welded WL zone. A typical example was shown in Fig. 4b, using the same CDF technique based on the "boundary double diffraction effect" of the overlapped region. It appears that a high energy status is introduced onto grain boundaries after IFW operation. The dislocation density can be reduced by PWHT to some degree but cannot be reduced to the original level of parent microstructure. The increase in stored energy due to plastic deformation was also represented by much increased dislocation density inside grains. The detailed work will be published elsewhere [10].
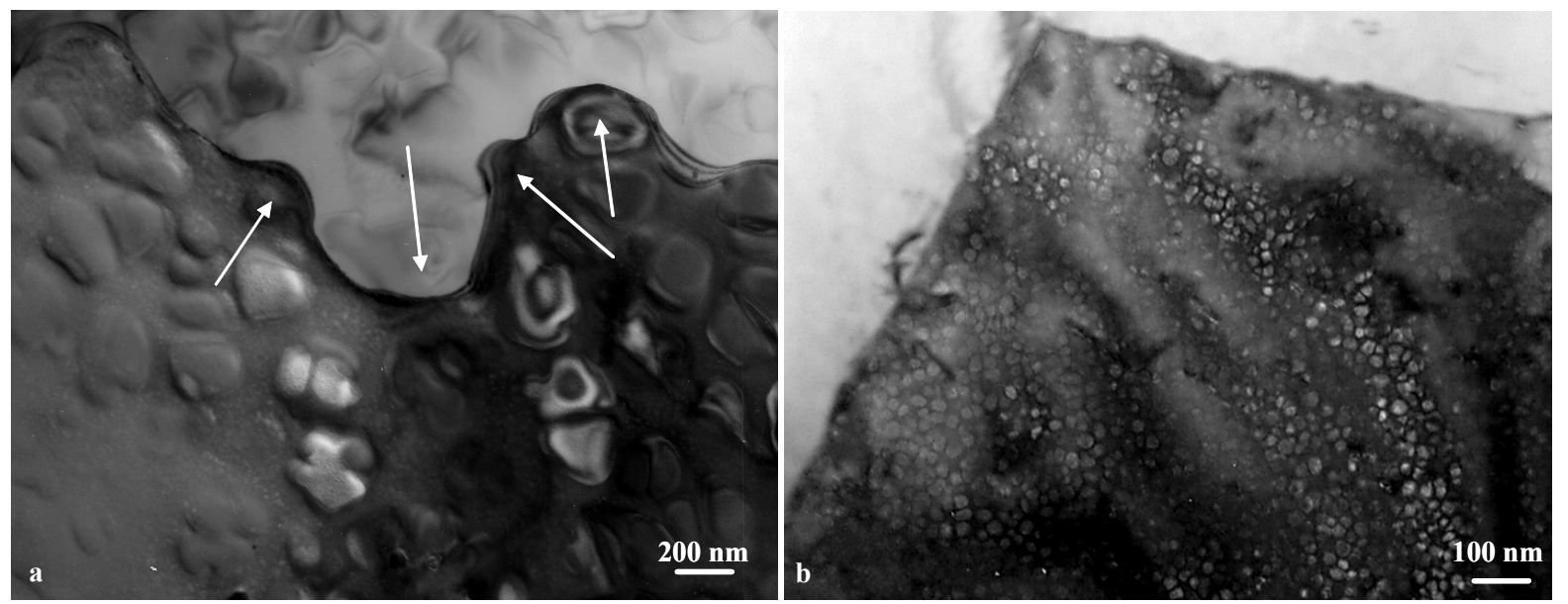

Fig. 3 TEM centred dark field (CDF) micrographs showing the high-angle grain boundary (a) in parent RR1000 and (b) in the WL zone of a RR1000 weld in as-welded condition

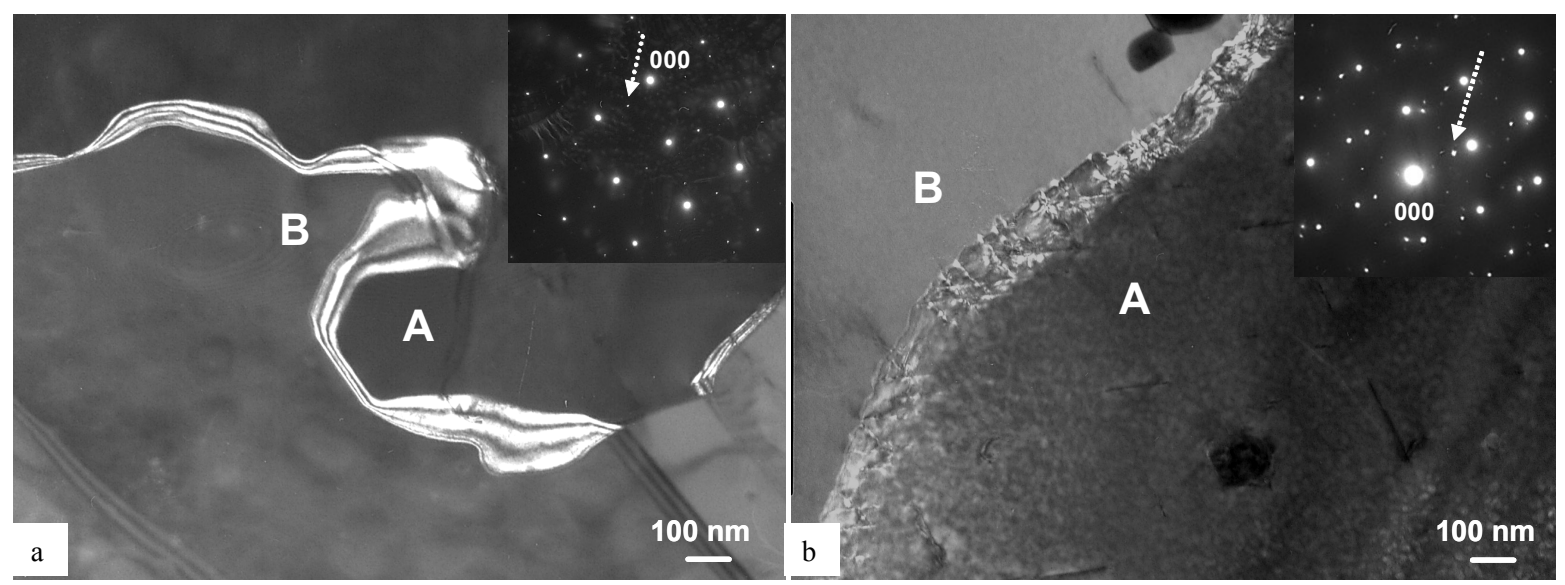

Fig. 4 TEM CDF images showing (a) a relatively clean and convoluted grain boundary in parent RR1000 and (b) dislocations segregated on the grain boundary in the WL zone. 
4) Grain boundary microchemistry. Small amounts of carbides and borides (no more than 3\% of grain boundaries have been decorated with such precipitates) were detected in the WL zones after PWHT. Figs. 5a and 5b show the grain boundary borides before and after IFW. Compared with block shaped discrete $M_{5} B_{3}$ boride in parent alloy, very fine $M_{5} B_{3}$ borides precipitated almost continuously along the grain boundaries in the WL zone. A small amount of carbides were also observed to stay along the grain boundaries in the WL zone. As shown in Fig. 6a, nanometer-sized $\mathrm{M}_{23} \mathrm{C}_{6}$ carbides precipitated semicontinuously along a grain boundary (arrowed) in the WL zone after PWHT. The insert in (a) was taken from the carbides showing a $[001]_{\gamma} / /[001]_{\mathrm{M} 23 \mathrm{C} 6}$ zone axis. TEM EDX spot analysis revealed that the $\mathrm{M}_{23} \mathrm{C}_{6}$ carbides along the boundary are enriched significantly in $\mathrm{Cr}$ and in Mo, but depleted significantly in Ni and Co (Fig. 6b). Correspondingly, there is a Cr-depletion zone in the vicinity of the boundary on the both sides.
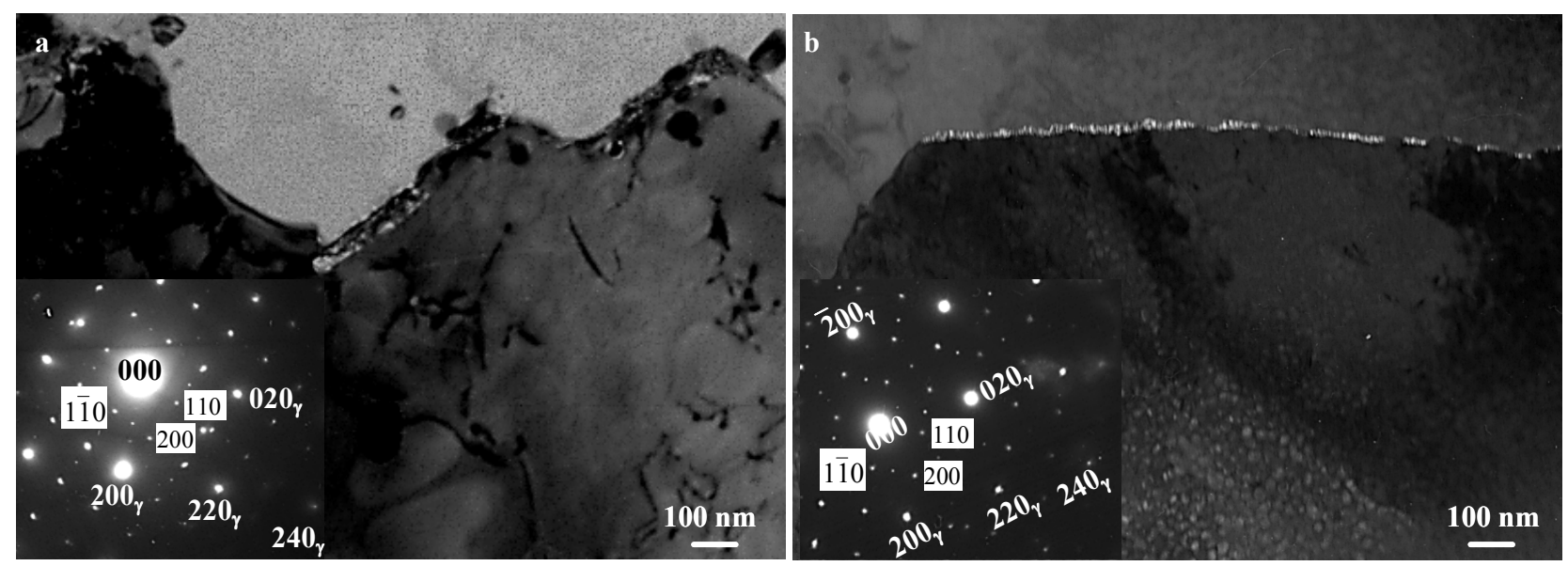

Fig. 5 TEM CDF images showing (a) discrete $\mathrm{M}_{5} \mathrm{~B}_{3}$ borides along a grain boundary in parent RR1000 and b) continuous $\mathrm{M}_{5} \mathrm{~B}_{3}$ borides along a grain boundary in the WL zone after a post weld heat treatment (PWHT)
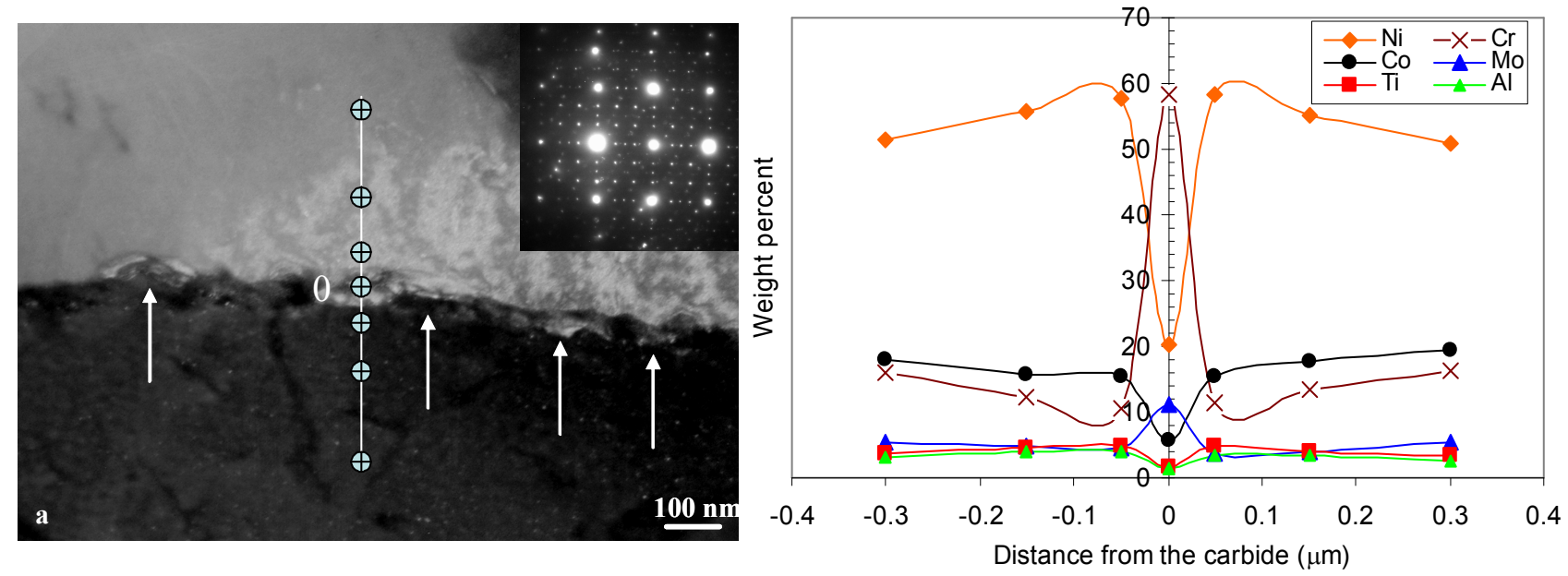

Fig. 6 (a) TEM CDF image showing $\mathrm{M}_{23} \mathrm{C}_{6}$ carbides along a grain boundary (arrowed) in the WL zone after a PWHT..(b) TEM EDX spot analysis reveals that the $\mathrm{M}_{23} \mathrm{C}_{6}$ is enriched significantly in $\mathrm{Cr}$ and in $\mathrm{Mo}$, but depleted significantly in Ni and Co.

Uni-modal distribution of fine $\gamma^{\prime}$ precipitates in the weld line zone. In contrast to a tri-modal distribution of $\gamma^{\prime}$ in FG RR1000, a unimodal distribution of fine $\gamma^{\prime}$ particles is produced in high density in the WL zone after IFW. The strengthening phase $\gamma^{\prime}$ have been changed fundamentally in terms of 1) size, 2) composition and 3) morphology. The changes are described below in detail.

1) The size. The size of the reprecipitated $\gamma^{\prime}$ is very fine, from a few $\mathrm{nm}$ to up to $\sim 20 \mathrm{~nm}$, see Fig. $7 \mathrm{a}$. This is very different from the size of primary $\gamma^{\prime}(1-2 \mu \mathrm{m})$ and secondary $\gamma^{\prime}(80-300 \mathrm{~nm})$, and even different from tertiary $\gamma^{\prime}(<80 \mathrm{~nm})$ in parent material (Fig. 7b). As mentioned before, the very fine size of the re-precipitated $\gamma^{\prime}$ is produced by a very fast cooling immediately after IFW. The initial cooling rate in weld interface region was estimated to be in a range of $80-130^{\circ} \mathrm{C} \mathrm{s}^{-1}[1,2]$. The fast 

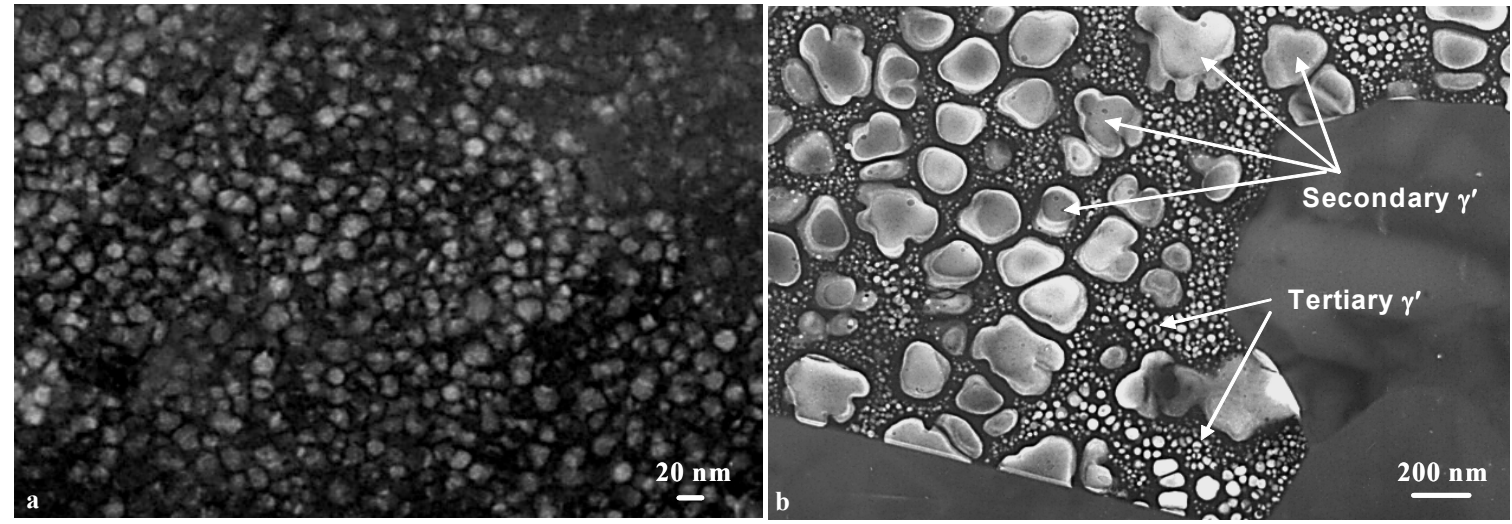

Fig. 7 TEM CDF images showing (a) a uni-modal distribution of fine spherical $\gamma^{\prime}$ in high density in the WL zone of a as-welded FG-FG RR1000 weld and (b) a bi-modal distribution of intragranular secondary $\gamma^{\prime}$ and tertiary $\gamma^{\prime}$ in a FG parent RR1000 .
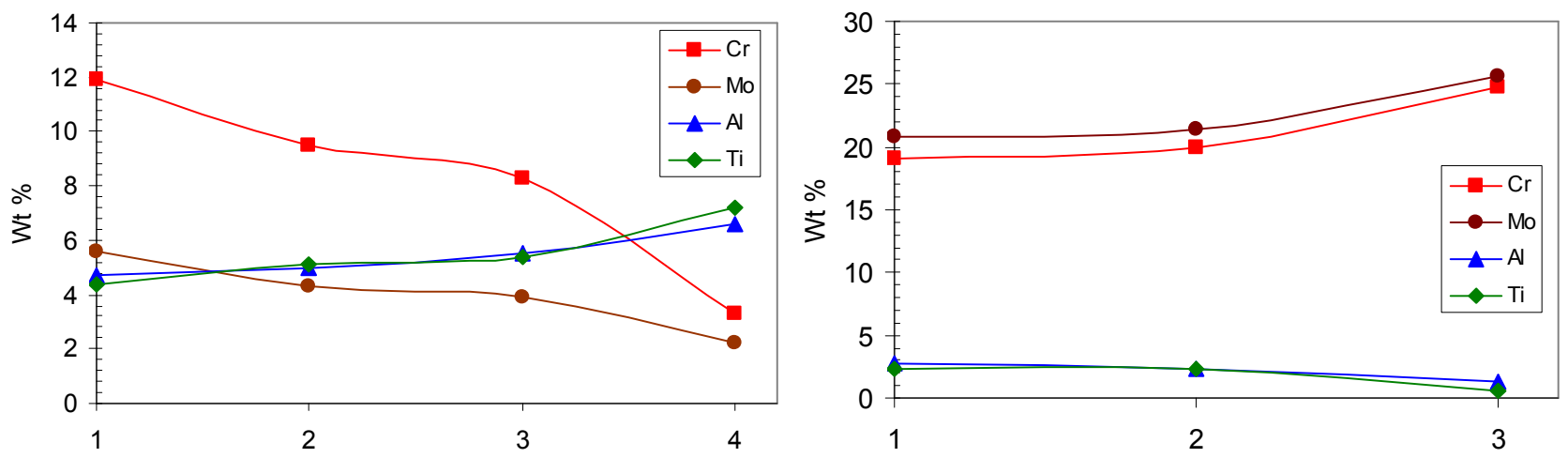

Fig. 8 Comparison of EDX results in chemical composition: (a) between the reprecipitated $\gamma^{\prime}$ (aswelded and after PWHT) in WL zone and the parent tertiary and secondary $\gamma^{\prime}$ and (b) between the grain boundaries in WL zone before and after PWHT and in parent material.

cooling results in a large degree of undercooling, which suppresses the early precipitation of $\gamma^{\prime}$ and forces the $\gamma$ phase in the WL zone to be highly supersaturated with all $\gamma^{\prime}$-forming elements until at a lower temperature, at which a large number of nucleation sites can be generated.

2) The composition of the reprecipitated $\gamma^{\prime}$. A tentative TEM EDX investigation was conducted to reveal the composition of the reprecipitated $\gamma^{\prime}$ particles and the surrounding $\gamma$ matrix as well as the straight grain boundaries in the WL zone. Errors come from the electron beam spreading and from the mixing volume of $\gamma^{\prime}$ and $\gamma$ in thickness direction since the two cannot be easily separated when electron beam penetrates through the analysed area. In order to reduce the interference error, a "cherry picking" method was used deliberately for the EDX analysis. Over 200 measurements have been made on re-precipitated $\gamma^{\prime}, \gamma$ matrix and grain boundary (also $\gamma$ ), respectively. The top 10 values that show highest $\mathrm{Ti}, \mathrm{Al}$ and $\mathrm{Ni}$ ( $\gamma^{\prime}$-forming elements) were taken to represent the reprecipitated $\gamma^{\prime}$. Similarly, the top 10 values that show highest $\mathrm{Cr}$, Co and Mo ( $\gamma$-forming elements) were taken to represent the $\gamma$ matrix and the grain boundary in WL zone.

Although the data in the analysed results are not accurate, the EDX results tend to indicate semiquantitatively that the elemental partitioning in the WL zone is different from that in base metal. The present EDX results reveal that a considerable degree of chemical imbalance is generated among the $\gamma^{\prime}$ particles, the $\gamma$ matrix and the $\gamma$ grain boundaries. As compared in Fig. 8a, both the reprecipitated $\gamma^{\prime}$ particles before and after PWHT contain less Al, Ti, Ni, Ta $\gamma^{\prime}$-forming elements but more $\mathrm{Cr}$, Co, Mo $\gamma$-forming elements than its parent counterparties. This is because very fast cooling forces the nucleation of $\gamma^{\prime}$ to occur at a quite low temperature at which sufficient diffusion of elements between $\gamma^{\prime}$ and $\gamma$ is suppressed to some degree. It also indicates that the PWHT used can not effectively remove the chemical imbalance. Accordingly, as shown in Fig. 8b, the grain boundaries in the WL zone before and after PWHT contain less Cr, Co, Mo but more Ti, Al, Ni, Ta than its parent counterpart. It is important to note that the $\mathrm{Cr}$ concentration along grain boundaries is no more than $20 \mathrm{wt} . \%$ in the WL zone under the non-equilibrium condition, which is about $5 \mathrm{wt}$. \% less than in the base metal in an equilibrium condition. This may reduce the oxidation resistance of the grain boundaries in WL zone. 
3) The morphology of the reprecipitated $\gamma^{\prime}$. The fine $\gamma^{\prime}$ reprecipitated under fast cooling is spherical in shape. The number density is very high in the WL zone. The spherical morphology and the very high number density of the reprecipitated $\gamma^{\prime}$ in the WL zone are shown in Figs. 7a. It was well known that the spherical shape of the fine reprecipitated $\gamma^{\prime}$ results from the small interfacial energy and elastic strain [11-13]. The former is proportional to the $\gamma / \gamma^{\prime}$ interface area and the latter is proportional to the volume of $\gamma^{\prime}$ particle. The elastic strain is determined mainly by the lattice mismatch between $\gamma$ and $\gamma^{\prime}$. In view of the size, shape and distribution of the reprecipitated $\gamma^{\prime}$ particles, the value of the lattice mismatch between the reprecipitated $\gamma^{\prime}$ and $\gamma$ matrix in the WL zone is expected to be smaller than that between parent $\gamma^{\prime}$ and $\gamma$ matrix in parent RR1000.

\section{Summary}

A uniform and fine grain structure forms throughout the WL zone, consisting of equiaxed grains of a few microns in size. Unlike the parent microstructure, the recrystallised grains inside the WL zones show straight and smooth grain boundary morphology. A significant increase in stored energy in the narrow WL zone is noticed after IFW operation both in as-welded and PWHT conditions. Small amounts of carbides and borides are observed to precipitate at grain boundaries in the WL zones after PWHT. However, the grain boundary precipitation is not a significant phenomenon in the WL zone for the RR1000 IFW welds examined.

In contrast to a tri-modal distribution of $\gamma^{\prime}$ particles in FG RR1000, a unimodal distribution of fine $\gamma^{\prime}$ particles is reprecipitated in high density in the WL zone. The mean size of the reprecipitated $\gamma^{\prime}$ is very fine. The fine $\gamma^{\prime}$ reprecipitated under fast cooling is spherical in shape. The number density is very high. On welding, a considerable degree of chemical imbalance is generated among the reprecipitated $\gamma^{\prime}$ particles, the $\gamma$ matrix and the $\gamma$ grain boundaries. The re-precipitated $\gamma^{\prime}$ contains less Al, Ti, Ni, Ta $\gamma^{\prime}$-forming elements but more $\mathrm{Cr}$, Co, Mo $\gamma$-forming elements than its parent counterparties, whereas the $\gamma$ matrix and grain boundaries contain less $\mathrm{Cr}, \mathrm{Co}$, Mo but more Ti, Al, $\mathrm{Ni}$, Ta than its parent counterpart.

\section{Acknowledgements}

Part of this research has been undertaken in the PANACEA (Processing of an Advanced Nickel Ally for Critical Engine Applications) Project (TP/4/MHT/1/22012), which forms part of the UK government Technology Strategy Board Programme. Rolls-Royce plc and Birmingham University would like to acknowledge the financial support provided by the Technology Strategy Board. The authors would also like to thank Colin Small of Rolls-Royce plc for co-ordination of the PANACEA Project and Rolls-Royce plc for permission to publish this work.

\section{References}

[1] J.P. Ferte: J. de Physique IV Vol. 3 (1993), p.1019

[2] M. Soucail, A. Moal, L. Naze, E. Massoni, C. Levaillant, in: Superalloys 1992, proceedings of the 7th International Symposium on Superalloys; 1992. TMS. p.847

[3] M. Preuss, J.W.L. Pang, P.J. Withers, and G.J. Baxter: Met. Mat. Trans Vol. 33A (2002), p. 3215.

[4] Z.W. Huang, H.Y. Li, M. Preuss, M. Karadge, P. Bowen, S. Bray and G. Baxter: Met. Mat. Trans. Vol. 38A (2007), p.1608

[5] M. Preuss, J. Quinta da Fonseca, I. Kyriakoglou, P.J. Withers and G.J. Baxter, in: Superalloys 2004, edited by K.A. Green, T.M. Pollock, H. Harada, T.F. Howson, R.C. Reed, J.J. Schirra, and S. Walston, TMS Warrendale, PA, (2004), p. 477.

[6] D. Roder, D. Helm, S. Neft, J. Albrecht, G. Luetjering, in: Proc. 6th Intern. Conf. on Superalloys 718, 625, 706 and Derivatives, Ed. E.A.Loria, TMS, Warrendale, USA, (2005), p. 649

[7] H.Y. Li, Z.W. Huang, S. Bray, G. Baxter and P. Bowen: Mater. Sci. Techn. Vol. 23 (2007), p. 1408

[8] M.F. Henry, Y.S. Yoo, D.Y. Yoon and J. Choi: Metall. Trans 24A (1993), p.1733

[9] R.J. Mitchell, H.Y. Li and Z.W. Huang: J Mater Proc Techn Vol. 209 (2008), p.1011

[10] Z.W. Huang, H.Y. Li, G.J. Baxter, S. Bray, M Hardy and P. Bowen, unpublished work, 2010

[11] R.A. Ricks, A.J. Porter and R.C. Ecob: Acta Metall. Vol. 31(1983), p. 43

[12] T. Grosdidier, A. Hazotte and A. Simon: Mater Sci Eng Vol. A256 (1998), p.183

[13] R.J. Mitchell, M. Preuss, M.C. Hardy and S. Tin: Mater Sci Eng Vol. A423 (2006), p. 282 